\title{
A prospective Study on the Evolution of Airtightness in 41 low energy Dwellings
}

\author{
Stijn Verbeke $^{1,2,3^{*}}$, and Amaryllis Audenaert ${ }^{1}$ \\ ${ }^{1}$ University of Antwerp, Energy and Materials in Infrastructure and Buildings (EMIB), Antwerp, Belgium \\ ${ }^{2}$ Unit Smart Energy and Built Environment, Flemish Institute for Technical Research (VITO), Boeretang 200, B-2400, Mol, Belgium \\ ${ }^{3}$ Building and Districts Energy Assessment, EnergyVille, Thor Park 8310, B-3600, Genk, Belgium
}

\begin{abstract}
Airtightness of the building envelope is an important parameter affecting the performance of (low energy) buildings. In case the airtightness is effectively measured, this is typically only done once as part of the commissioning of the construction work. Several factors could affect the evolution of the airtightness of the envelope after the building is constructed. In this work, follow-up airtightness tests have been carried out to investigate the evolution of the performance in the interval of 0.5 up to 12 years compared to the original pressurisation test. The results on 41 low-energy dwellings indicate that the airtightness is indeed not a fixed value over time. Of the 41 buildings, 29 display an increased air permeability resulting in an increase of up to $200 \%$ in relative terms or up to $1.36 \mathrm{ACH}_{50}$ (air changes per hour at $50 \mathrm{~Pa}$ pressure difference $\left[\mathrm{h}^{-1}\right]$ ). Conversely, four of the buildings in the dataset show a significant improvement of the airtightness; resulting in a decrease of air leakage of up to $-1.19 \mathrm{ACH}_{50}$. Analysis of the data shows that on average the air permeability at $50 \mathrm{~Pa}$ pressure difference increased by $38 \%$, but with great variation depending multiple factors such as initial airtightness value and construction type. This corresponds to an average increase of the specific air permeability of the building envelope of 0.15 $\mathrm{m}^{3} /\left(\mathrm{h} \cdot \mathrm{m}^{2}\right)$. Most of the buildings under analysis are low energy buildings or passive houses which were very airtight at time of construction. Despite the observed evolution in air permeability, many buildings under investigation can still be considered sufficiently airtight a few years after initial construction.
\end{abstract}

\section{Introduction}

Environmental, financial and policy factors are pushing the construction sector towards increased energy performance of the building stock. For newly constructed buildings, the designer can choose from a myriad of design strategies. Traditionally, the focus has been mostly on reducing the thermal transmittance of building envelope components and improving the system efficiency of HVAC systems.

Air infiltration through the building envelope can also be an important factor, as a leaky envelope could contribute to 5-10\% additional heating energy demand in buildings, and even higher relative shares in case of low energy buildings [1].

Airtightness can be improved by implementing airtight construction components, better detailing of construction joints and good workmanship [2]. Improved airtightness will not only be beneficial with regard to the energy demand, but can also reduce the risks of moisture damage in building envelope components and improve acoustic conditions [3]. In poorly ventilated buildings, air infiltration could assist in generating sufficient air exchanges with the outdoors, but conversely air leakages will hinder the efficient operation in buildings which are equipped with dedicated ventilation systems. Furthermore, air leaks can impact the indoor air quality by polluting the air (fibres, dust, mold, etc.) when air passes through the cracks and crevices [4].

The airtightness of the envelope is one of the factors affecting the heating and cooling demand of buildings and therefore it is increasingly subject to guidelines and regulations on the energy performance of buildings. Firstly, it can be assessed as a separate performance indicator, e.g. the Passive House certification scheme requires a maximum air exchange rate at a $50 \mathrm{~Pa}$ pressure difference $\mathrm{n}_{50}\left(\mathrm{ACH}_{50}\left[\mathrm{~h}^{-1}\right]\right)$ of $0.6 \mathrm{ACH}_{50}$. Alternatively, it can be part of the calculation procedure of more encompassing performance indicators. This can for example be the case in national implementations of the European Energy Performance of Buildings Directive (EPBD), which requires member states to define targets for the energy performance of individual buildings and develop a methodology to calculate the energy performance score.

An example of such method is the energy performance regulation in Flanders, which is largely based on the EN ISO 52000 series of standards. EN ISO 52016-1 is the standard which describes the procedures to calculate the heating and cooling energy demands,

* Corresponding author: stijn.verbeke@uantwerpen.be 
through balancing the energy flows as a result of the combined effects of envelope thermal insulation, airtightness and ventilation, the building mass, solar heat gains and internal heat gains from occupants and appliances [5]. In the Flemish methodology for new constructions, a default specific envelope air leakage rate of the exposed building envelope of $\mathrm{q}_{\mathrm{E} 50}$ equal to 12 $\mathrm{m}^{3} /\left(\mathrm{h} \cdot \mathrm{m}^{2}\right)$ is assumed. This value represents the air flow through a square meter of external building envelope which is subject to a pressure difference of $50 \mathrm{~Pa}$. This default value can be replaced with actual measurement data retrieved through a fan pressurisation test. If this reported value is lower than the default value, this will result in improved energy performance scores for a building, or - alternatively - reduced investments in other energy saving measures to reach the same energy performance objective. Supplementary to including airtightness values in the overall building energy performance calculation routines, some EU member states have also included minimum airtightness requirements in their building codes [6].

The airtightness is typically measured during construction or closely thereafter. Implicitly, energy performance assessment methods suppose that the airtightness is a static performance quality of the building envelope. In this research a post-occupancy evaluation is performed to check whether the reported air permeability will indeed remain stable over a longer period of time. Prior studies reported in literature have indicated that significant changes in air permeability might effectively be expected. Bracke et al. report a median increase of $25 \%$ air infiltration increase in 15 passive houses which are tested again 13 to 19 months after the original test [7]. In a series of 52 passive houses monitored by the Fraunhofer Institute for Building Physics, it was concluded that air infiltration values increased from $\mathrm{n}_{50}=0.37 \mathrm{ACH}_{50}$ right after construction to $0.46 \mathrm{ACH}_{50}$ two years later, i.e. an increase of $24 \%$ [8], [9]. Proskiw and Eng however report some changes in airtightness of 24 dwellings after a three-year period, but conclude that the changes are small and not of a practical significance [10].

This paper expands the knowledge on air permeability robustness through reporting the results of a survey on 41 low-energy dwellings in Belgium. In this study, the time intervals between the initial and followup measurements is generally longer (up to twelve years) compared to prior studies.

\section{Measuring airtightness}

Being an important parameter affecting the heating and cooling energy demand and indoor air quality, various methods to quantify the air permeability of the building envelope have been developed. Many low energy buildings are currently tested at times of construction, since for low energy buildings with improved thermal insulation characteristics the energy losses due to air infiltration can represent an important share of the total energy demand. Two methods are widely used: tracer gas test methods and the fan pressurisation method. The actual air infiltration through the building envelope is not only affected by the cracks and openings in the envelope, but also by environmental parameters which affect the pressure difference over the envelope such as wind speed and orientation and temperature differences. Tracer gas methods are used to assess airtightness during normal operation conditions. Using this method, an inert gas is introduced to a room or a building, and the evolution of the concentration is monitored over time. Three different set-ups of tracer gas methods are possible: a constant injection rate, a controlled injection to reach a constant concentration of the mixed indoor air and a concentration decay method [11]-[13]. The concentration decay is the most commonly accepted since its implementation is the easiest and it requires the least amount of tracer gas [14].

The most widely used method to measure airtightness of buildings is however not a tracer gas method, but the fan pressurisation method, which is also commonly referred to as 'blowerdoor test'. EN ISO 9972:2015 describes the set-up and procedures to execute this test [15]. Instead of assessing the air infiltration during normal operation of the building with fluctuating environmental parameters, this test imposes pressure differences by means of a fan which is installed in one of the envelope openings (see Fig. 1). During the test, the fan causes both positive and negative pressure differences and measures the corresponding air flow needed to sustain a given pressure difference. Next, the data are processed to derive a single figure denoting the air permeability of the building envelope. Commonly, this is expressed as an air leakage rate at a $50 \mathrm{~Pa}$ pressure difference $\mathrm{q}_{50}\left[\mathrm{~m}^{3} / \mathrm{h}\right]$, a specific air permeability per envelope area $\mathrm{q}_{\mathrm{E} 50}\left[\mathrm{~m}^{3} /\left(\mathrm{h} \cdot \mathrm{m}^{2}\right)\right]$, or as the amount of air changes per hour at $50 \mathrm{~Pa}: \mathrm{n}_{50}\left(\mathrm{ACH}_{50}\right)\left[\mathrm{h}^{-1}\right]$. A widely used rule-of-thumb for relating the results from a fan pressurisation test to air exchanges during normal building operation is to apply a fixed conversion factor of $1 / 20$ [12], [16].

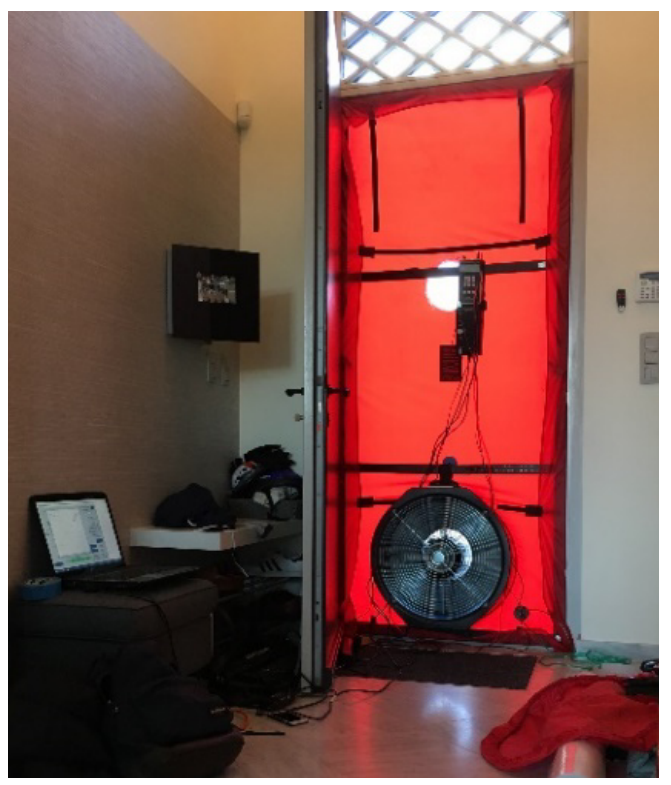

Fig. 1. Installed fan pressurisation test set-up 
In the Flemish energy performance regulations for buildings, measurement results of a fan pressurisation test can replace the default infiltration values used in the calculation methodology. At the onset of the regulations in 2006, airtightness was only measured in 1 out of 40 new constructions according to figures reported by the Flemish Energy Agency VEA [17]. By 2017, 86\% of new constructions issued an airtightness test. The average measured air permeability $\mathrm{q}_{\mathrm{E} 50}$ of $3.6 \mathrm{~m} /\left(\mathrm{h} \cdot \mathrm{m}^{2}\right)$ is significantly lower than the default value of 12 $\mathrm{m}^{3} /\left(\mathrm{h} \cdot \mathrm{m}^{2}\right)$.

\section{Data collection method}

Once a building has been subject to an air pressurisation test, the achieved performance results are implicitly considered to remain valid. In practice however, one can imagine that air permeability of a given building envelope could change over time due to wear and tear of materials, minor movements in the construction and construction components, small refurbishments undertaken by the home owners, etc. This paper describes the results of an exploratory study investigating whether indeed significant evolutions in air permeability can be detected. To gather these data, a set of 41 dwellings - all located in Belgium - is subjected to a second fan pressurisation test. The time interval between the first and second test ranges from six months to almost twelve years.

The selection of test case dwellings and retrieval of original fan pressurisation test data was done by contacting building owners, architects, contractors and businesses undertaking fan pressurisation tests. While undertaking such tests is becoming more mainstream, this was not the case for buildings which have been constructed five to ten years ago. Back then, this test was mainly executed by home owners pursuing passive house certification. This causes the sample of buildings to be biased towards (very) low energy houses.

A renewed test was executed by students and university staff using a Minneapolis Blower Door with DG-700 controller and following the guidelines of EN ISO 9972:2015 and the additional technical specifications of STS-P 71-3 required by the Flemish Energy Agency.

\section{Results}

\subsection{Originally reported air infiltration rate}

Fig. 2 displays the reported air infiltration results at the time of construction. The originally declared air infiltration rate is $0.94 \mathrm{ACH}_{50}$ on average. The median is $0.48 \mathrm{ACH}_{50}$ and standard deviation amounts to 1.35 . Specific leakage per square meter building envelope is also reported for most cases. For some of the dwellings details on envelope area are missing and hence this value is not depicted in Fig. 2. These results indicate that the set of buildings under investigation was characterised by a very low initial air permeability.

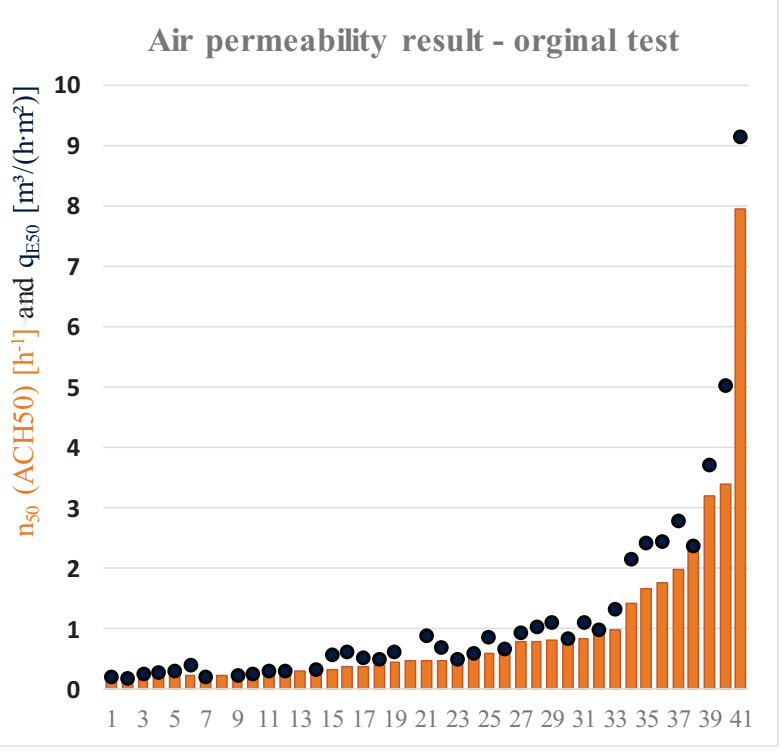

Fig. 2. Reported results of fan pressurisation test at time of construction. Orange bars denote measured air changes per hour at $50 \mathrm{~Pa}\left(\mathrm{ACH}_{50}\right)\left[\mathrm{h}^{-1}\right]$; the blue dots depict the measured envelope specific air permeability $\mathrm{q}_{\mathrm{E} 50}\left[\mathrm{~m}^{3} /\left(\mathrm{h} \cdot \mathrm{m}^{2}\right)\right]$

All but one cases displays a specific air permeability which is lower than the average of all new residential buildings undergoing an air infiltration test in the Flemish region (i.e. $\mathrm{q}_{\mathrm{E} 50}=3.6 \mathrm{~m} /\left(\mathrm{h} \cdot \mathrm{m}^{2}\right)$ ). Also compared to building regulations across Europe (see e.g. overview of Kraus and Kubecková [6]) these buildings are performing very well. Of the 41 buildings, 25 would comply to the requirements of Passive House Institute demanding a maximum $\mathrm{n}_{50}$ value of $0.6 \mathrm{ACH}_{50}$.

\subsection{Time interval between measurements}

Fig. 3. displays the average time interval between the original fan pressurisation test - during or shortly after construction - and the follow-up test as part of this research. The average time interval between both fan pressurisation tests amounts to 1841 days, i.e. 5 years (median 1794 days, standard deviation 883 days).

It is apparent that some of the houses with the lowest time interval between both measurements (hence the most recently constructed dwellings in the data set) have an air permeability which is higher than average in the data set. This bias is due to the fact that the older dwellings under investigation are predominantly certified passive houses. In recent years air permeability testing became more common. Therefore, for more recent constructions data could also be sourced from buildings which have undergone an air permeability test as part of their certification in the framework of the official EPBD requirements, but not necessarily with the aspiration to achieve passive house certification status. 


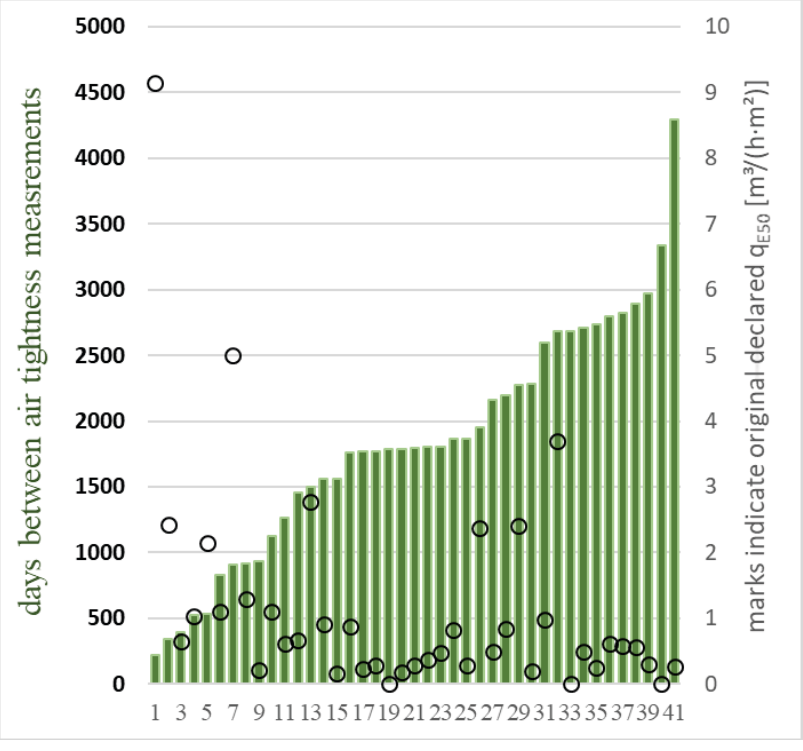

Fig. 3. Histogram of time interval between the initial and follow-up fan pressurisation tests for the 41 case study buildings. The circular marks depict the measured envelope specific air permeability $\mathrm{q}_{\mathrm{E} 50}\left[\mathrm{~m}^{3} /\left(\mathrm{h} \cdot \mathrm{m}^{2}\right)\right]$

\subsection{Deviation in airtightness between measurements}

The outcomes of both airtightness tests are now compared. Fig. 4 indicates that for most cases an increased air permeability can be observed. For eight of the 41 cases, both reported values deviate less than $10 \%$. Four cases prove to have become more airtight, with one dwelling reducing from $3.4 \mathrm{ACH}_{50}$ to $2.2 \mathrm{ACH}_{50}$. The majority of the buildings however - 29 buildings in the set of 41 - displayed a significant increase in air permeability, ranging from $11 \%$ to $200 \%$. On the whole dataset, an average increase of $38 \%$ can be observed.

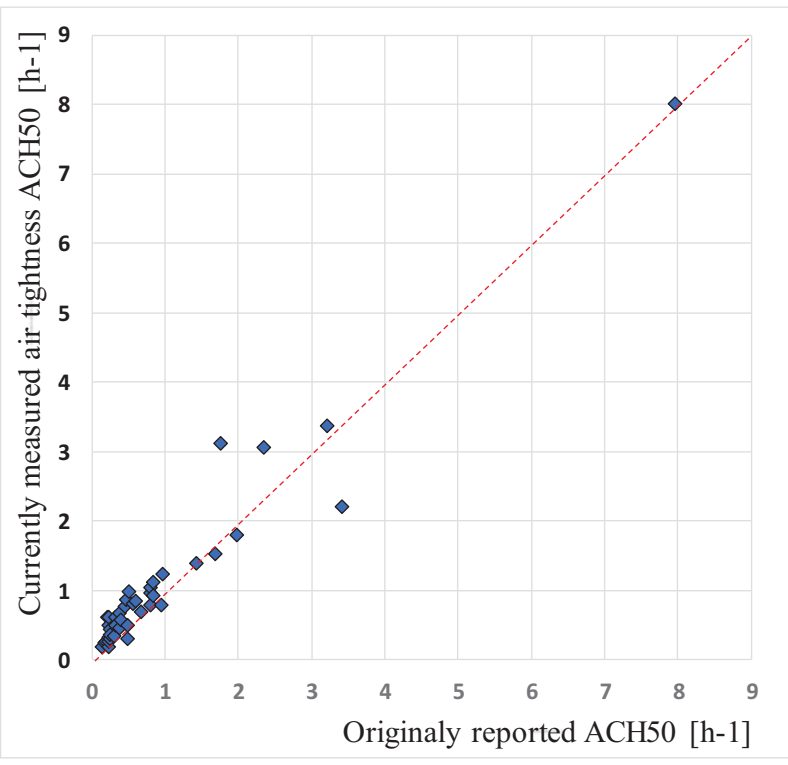

Fig. 4. Contrasting measured air changes per hour at $50 \mathrm{~Pa}$ $\left(\mathrm{ACH}_{50}\right)\left[\mathrm{h}^{-1}\right]$ between initial fan pressurisation test and renewed test.
Given the low initial air permeability, a slight increase or decrease can result in large relative changes. This is for example the case for one dwelling with an original air permeability of $0.2 \mathrm{ACH}_{50}$. Eleven years after the initial test, an air permeability of $0.6 \mathrm{ACH}_{50}$ is reported. Although a considerable increase in relative terms, this building can still be considered sufficiently airtight to (just) satisfy requirements of newly constructed passive houses, and hence outperforms the vast majority of new constructions in the current market.

In absolute numbers, the average evolution of air permeability is an increase of $0.14 \mathrm{ACH}_{50}$ (median 0.11, standard deviation 0.34). The maximum reported increase amounts to $+1.36 \mathrm{ACH}_{50}$, while the largest decrease results in $-1.19 \mathrm{ACH}_{50}$. Of the 25 dwellings which denoted an initial airtightness of less than 0.6 $\mathrm{ACH}_{50}$, seven did no longer reach this target at the time of the renewed assessment. The maximum reported $\mathrm{n}_{50}$ value for this subset amounts to $0.98 \mathrm{ACH}_{50}$ (from an initial value of $0.51 \mathrm{ACH}_{50}$ ).

In terms of specific air permeability $\mathrm{q}_{\mathrm{E} 50}\left[\mathrm{~m}^{3} /\left(\mathrm{h} \cdot \mathrm{m}^{2}\right)\right]$ similar results can be noted as for the absolute variations in air changes per hour.

\subsection{Relation between building age and airtightness evolution}

Fig. 5 shows the relative changes in measured airtightness in relation to the time interval between both measurements for each of the 41 cases.

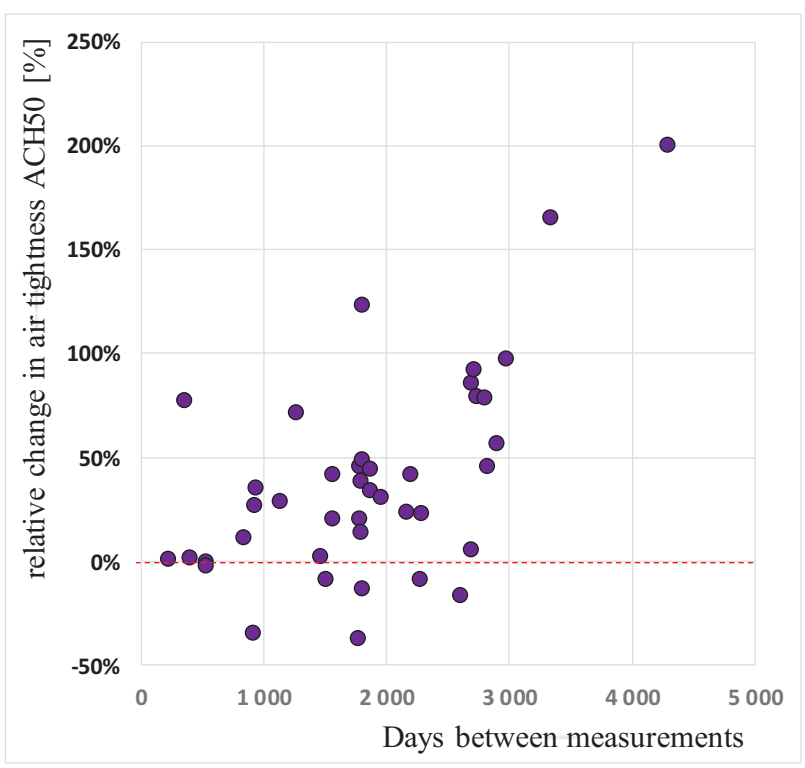

Fig. 5. Relative changes in measured air changes per hour at 50 $\mathrm{Pa}\left(\mathrm{ACH}_{50}\right)\left[\mathrm{h}^{-1}\right]$ in function of time interval between initial test and new test for 41 case study buildings

On average, there is a slight tendency for increased air permeability as the time interval increases. The specific air permeability $\mathrm{q}_{\mathrm{E} 50}$ increases on average by $0.15 \mathrm{~m} /\left(\mathrm{h} \cdot \mathrm{m}^{2}\right)$. A simple linear regression with zero intercept would suggest an annual increase of air permeability of $0.0275 \mathrm{~m} /\left(\mathrm{h} \cdot \mathrm{m}^{2} \cdot \mathrm{yr}\right)$. Given the low number of observations and high variability in the data, 
such linear regression can however not be considered statistically relevant $\left(\mathrm{R}^{2}<0.001\right)$. Furthermore, the data do not represent a longitudinal test following up a set of buildings at multiple time intervals. So while on average an increased air permeability can be observed after a period of multiple years, based on this data set no conclusions can be drawn with regard to the origins and potential future evolution of air permeability evolutions. This figures could as well be explained by a continued aging and wearing of airtightness measures as by discrete events during the lifetime of the constructions.

\section{Discussion}

Based on the 41 observations in the test, one can conclude that the air permeability is not a robust parameter of the building envelope. While other properties affecting the building performance such as thermal transmittance of envelope insulation materials [18] or the efficiency of HVAC systems [19] are also known to potentially be subject to degradation over time, the deterioration of airtightness measures proves to be much more outspoken. This is in line with other findings in literature, reporting increases in permeability in the order of magnitude of $25 \%$ [7]. In this study, the average increase of $38 \%$ is higher compared to other values reported in literature. One contributing factor could be the larger time interval between the initial test and the follow-up measurements, amounting to a median time interval of 5 years between both tests. Next, the initial air permeability of the set of buildings under investigation is very low (average $\mathrm{n}_{50}=0.94 \mathrm{ACH}_{50} ;$ median $\mathrm{n}_{50}=0.48$ $\mathrm{ACH}_{50}$ ) and therefore small changes in absolute values can result in significant changes in relative numbers.

Although on average the building envelopes have shown to become more permeable to air over time, interestingly four dwellings displayed an improvement of airtightness of respectively $38 \%, 35 \%, 17 \%$ and $14 \%$ compared to the initial n50 value. For one case with an initial n50 value of $0.22 \mathrm{ACH}_{50}$, the improvement to 0.19 $\mathrm{ACH}_{50}$ is small and could potentially be solely attributed to measurement uncertainties. One other building however is characterised by a very significant reduction of $1.19 \mathrm{ACH}_{50}$ (from $\mathrm{n}_{50}=3.40$ to $2.21 \mathrm{ACH}_{50}$ ). A hypothesis is that this effect could potentially be attributed due to the timing of the initial fan pressurisation test. This test might have been undertaken when construction works were not fully completed, which is frequently done as such timing leaves more possibilities to seal minor leaks observed during the test. Further works on interior finishing could have further improved the performance. This hypothesis could not be validated by the current owner of the building.

Most buildings however display a significant increase of reported air permeability several years after the initial measurement. In the current study, the causes of this deterioration were not investigated in greater detail. Nevertheless, some specific observations could be made during execution of the second test. In some buildings the use of a fog dispenser and infrared thermography helped to pinpoint plausible causes of additional air leaks which were probably not present at time of construction (see Fig. 5). Most notably these were located at windows or doors with improper air sealing or slight deformations, and cables or ductwork installed after completion of the dwelling (e.g. to rooftop solar PV panels).

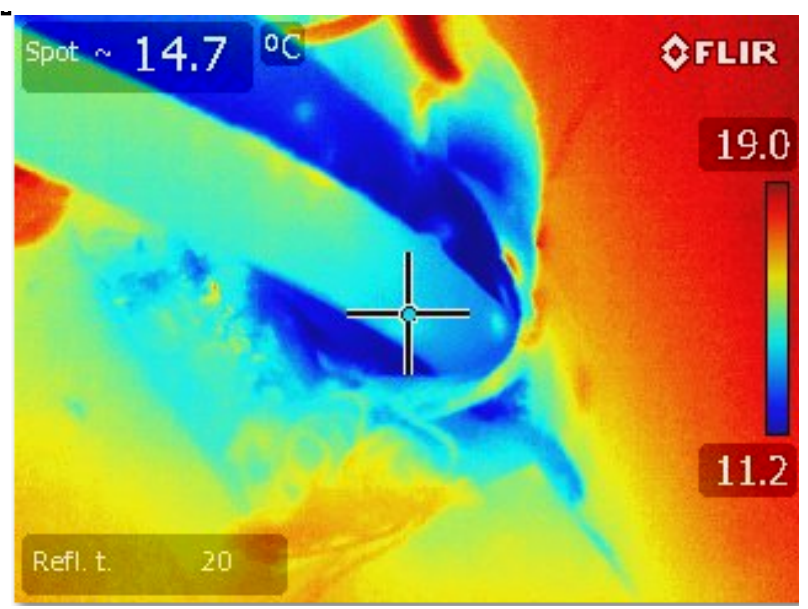

Fig. 5. Thermographic image of ductwork installed in one of the case study dwellings after initial fan pressurisation test. The lower surface temperatures in the vicinity of the ducts can be indicative of increased air infiltration.

The initial test and revisit have been performed by different people and using different equipment, which could also explain part of the variations. While pure measurement uncertainties should ideally display a normal variation, the human factor could introduce biased errors. Commercial entities performing pressurisations tests could have been tempted to be less strict on the guidelines and regulations for carrying out a fan pressurisation test (e.g. concerning which openings can be sealed during the test, position of doors and hatches inside the building, etc.), which could in turn result in lower declared values. If this would be the case, the observed deviations would (at least partly) not be due to aging and wearing of materials, but simply be the result of an initial underestimation of the airtightness.

\section{Conclusion and outlook}

This prospective study compared the airtightness of 41 dwellings with the airtightness reported closely after the initial construction. Time intervals between both tests ranged from six months to twelve years, with an average of five years. For the majority of buildings, the airtightness was observed to be not robust. In only eight cases, the deviation of both measurement results was less than $10 \%$ in either direction. While four buildings showed an better airtight envelope, for the majority of buildings a significant increase in air permeability of $11 \%$ to $200 \%$ could be found. For the full data set, the average evolution is a $38 \%$ increase in air permeability at a $50 \mathrm{~Pa}$ pressure difference. In absolute terms however, the increase in air infiltration is often rather limited, since most cases under study had low or very low initial air permeabilities. 
Further research will expand the sample size, especially towards buildings which were characterised by a somewhat higher initial air permeability. An increased sample size will also allow for further statistical analysis, including relating the deviations to building characteristic such as construction typology (e.g. timber frame versus masonry) and initial construction period. Furthermore, there is lack of evidence on identifying the causes for the observed evolution of air permeability of the building envelope.

We express our gratitude towards the technical staff and master students of construction engineering who executed the fan pressurisation measurements and the building owners and occupants for providing data and access to their buildings.

\section{References}

[1] A. Miszczuk, "Influence of air tightness of the building on its energy-efficiency in single-family buildings in Poland," MATEC Web Conf., vol. $117,2017$.

[2] C. Younes, C. a. Shdid, and G. Bitsuamlak, “Air infiltration through building envelopes: A review," J. Build. Phys., vol. 35, no. January, pp. 267-302, 2012.

[3] G. Raman, K. Chelliah, M. Prakash, and R. T. Muehleisen, "Detection and quantification of building air infiltration using remote acoustic methods," INTERNOISE 2014 - 43rd Int. Congr. Noise Control Eng. Improv. World Through Noise Control, no. January, 2014.

[4] W. R. Chan, W. W. Nazaroff, P. N. Price, M. D. Sohn, and A. J. Gadgil, "Analyzing a database of residential air leakage in the United States," Atmos. Environ., vol. 39, no. 19, pp. 3445-3455, 2005.

[5] CEN, "EN ISO 52016-1:2017: Energy performance of buildings - Energy needs for heating and cooling, internal temperatures and sensible and latent heat loads -- Part 1: Calculation procedures.” 2017.

[6] M. Kraus and D. Kubečkova, "Airtightness of Energy Efficient Buildings," Annu. Int. Conf. Archit. Civ. Eng. Singapore, 2013.

[7] W. Bracke, J. Laverge, N. Van Den Bossche, and A. Janssens, "Durability and Measurement Uncertainty of Airtightness in Extremely Airtight Dwellings," Int. J. Vent., vol. 14, no. 4, pp. 383-393, 2016.

[8] J. Reiß and H. Erhorn, "Messtechnische Validierung des Energiekonzepts einer großtechnisch umgesetzten Passivhausentwicklung in Stuttgart-Feuerbach," IBP-Bericht WP, vol. 117, 2003.

[9] H. Erhorn, H. Erhorn-Kluttig, and R. Carrié, "Airtightness requirements for high performance buildings," in Proceedings 29th AIVC

Conference 2008, 2008, pp. 25-32.
[10] G. Proskiw and P. Eng, "Variations in Airtightness of Houses Constructed with Polyethylene and ADA Air Barrier Systems Over a Three-Year Period," Therm. Insul. Build. Envel., vol. 20, no. April 1997, pp. 278-296, 1997.

[11] M. H. Sherman, "Tracer-gas techniques for measuring ventilation in a single zone," Build. Environ., vol. 25, no. 4, pp. 365-374, 1990.

[12] T. Patel, C. Mitsingas, J. P. Miller, and T. A. Newell, "Comparison of blower door and tracer gas testing methods for determination of air infiltration rates through building envelopes at normal operating conditions," ASME 2011 5th Int. Conf. Energy Sustain. ES 2011, no. PARTS A, B, AND C, pp. 1013-1019, 2011.

[13] ASTM E741, "Standard test method for determining air change in a single zone by means of a tracer gas dilution," 2000.

[14] S. Cui, M. Cohen, P. Stabat, and D. Marchio, "CO2 tracer gas concentration decay method for measuring air change rate," Build. Environ., vol. 84, pp. 162-169, 2015.

[15] EN ISO 9972:2015, "Determination of air permeability of buildings-Fan pressurization method," 2015.

[16] J. Kronvall, "Correlating Pressurization and Infiltration Rate Data-Tests of an Heuristic Model," Lund Inst. Technol. Div. Build., 1980.

[17] VEA, "EPB-CIJFERRAPPORT Procedures , resultaten en energetische karakteristieken van het Vlaamse gebouwbestand - periode 2006 2018. (in Dutch)," 2019.

[18] B. P. Jelle, "Traditional, state-of-the-art and future thermal building insulation materials and solutions - Properties, requirements and possibilities," Energy and Buildings. 2011.

[19] S. Baldi, T. Le Quang, O. Holub, and P. Endel, "Real-time monitoring energy efficiency and performance degradation of condensing boilers," Energy Convers. Manag., vol. 136, pp. 329-339, 2017. 